\title{
Enhanced Child Abuse Information Management System-The Nigeria Context
}

\author{
Ndubuisi Henry Odikwa ${ }^{1}$, Ukabuiro, Ikenna ${ }^{2}$, Akwaraonwu, Bright ${ }^{3}$ \\ ${ }^{1}$ Department of Computer Science, Abia State University, Uturu, Abia State, Nigeria \\ ${ }^{2}$ Department of Computer Science, Abia State University, Uturu, Abia State, Nigeria \\ ${ }^{3}$ Department of Computer Science, Michael Okpara University of Agriculture, Abia State, Nigeria
}

\begin{abstract}
The Child Abuse Information Management System is a research designed to create a platform where issues related to child abuse complaints will be domicile and attended to by human right activists and law enforcement agents in Nigeria as result of rising cases in child abuse. The computerized system will keep tracks of all the suspicious incidents of child abuse by generating reports, aid law enforcement agency based on numerous details deposited on the platform. For this implementation of this design, a lot of web related technology like CSS, XAMP, MYSQL were used as the back end and PHP programming language in the front end. Implementing this computerized system will play a crucial role in child welfare. The management system and data collection tools will meet with the Federal reporting requirements, it will also serve the information needs of an organizations, help inform management decisions and support caseworkers' interactions with children and families. After the creation and testing of this system, it proved a much easier, faster and efficient way for victims or observers to make reports about their previous or on going abuses.
\end{abstract}

Keywords: Child abuse, drug-peddling, human right activist, complaint platform

\section{INTRODUCTION}

A child is an individual that is below the age of eighteen (18) and under the care of either their parents or guardian. Children at this age need to be cared for, physically, emotionally and educationally. The future of the world depends on the children since every generation lives for certain period of time. For instance, there were children living in this world hundreds years ago, but they have passed that age of childhood and became great men and women. The world existence depends on the children. Child abuse has been defined in various ways however, the base line is that the child is intentionally molested or maltreated with a long time psychological effect. For instance, google 2020 defined Child abuse as any form of maltreatment by an adult which is violent or threatening for the child. On the other hand, [2] defined child abuse as the portion of harm done to a child who may be from human action or inaction that is proscribed or proximate and preventable. Preventable here implies that it is not accidental but intentionally inflicted on the child by perpetrator who does not care about the outcome. The rate of prevalence of child abuse in Nigeria is increasingly alarming. Its prevalence and kind vary from one region to another. Child abuse is not isolated to particular social groups or areas however, it is rampant in many of the world's poorer countries and even more so in Nigeria. According to [1] Child abuse covers a wide range of work activities and industries, such as using children for: domestic services, bus conducting, and car washing, drug-peddling and herding of livestock. Other forms of child abuse include involving children in: industrial work, street hawking, child trafficking, street begging, agriculture and mines, food processing, construction, sex industry, textile industry and tourism. Child abuse will in the long run affect the economy of the nation. As abused children may not be able to acquire adequate education that will enable them become different professionals that the country will be needing. Imagine a country without lecturers, teachers, doctors, engineers, pilots, and other professionals. Imaging, the supposed professional have been abused at childhood, instead of becoming lecturer they are now drugs addict; instead of becoming doctors they are now sex workers; instead of becoming engineers they are now kidnappers instead of becoming pilots they are now bandits, and at end affect the economy growth of the country. Without a computerized database management system it is almost impossible for a country to know the number of children that have been abused to enable it put measures in place to control and prevent the menace and the consequences of child abuse. You cannot control what you don't know.

\section{LITERATURE REVIEW}

\subsection{Concept of Child Abuse and Neglect}

Child abuse can be defined as causing or permitting any harmful or offensive contact on a Child's body; and any communication or transaction of any kind, which humiliates, shames, or frightens the child. Some child development experts go a bit further, and define child abuse as any act or omission, which fails to nurture the upbringing of the children [3].

[5] also defined child abuse and neglect as: "at minimum, any recent act or fare to act on the part of a parent or caretaker which results in death and serious physical' emotional harm, sexual abuse or exploitation, or an act or failure to act which presents an imminent risk or serious harm". In addition the oxford-advanced learner's dictionary of contemporary English defines it as the crime of harming a child in a physical, sexual or emotional away. 
It should be noted that any child of any sex, race, religion and socioeconomic background could fall victim to child abuse and neglect [6].

\subsection{Types of Child Abuse and Neglect}

Child abuse and neglect consists of any acts of commission or omission by a parent or other caregiver that results in harm, potential for harm, or the threat of harm to a child (0-18 years of age) even if the harm is unintentional [4]. The five main types of child maltreatment are: physical abuse, sexual abuse, emotional maltreatment, neglect, and witnessing domestic violence.

Evidence suggests that different types of abuse and neglect rarely occur in isolation and children who experience repeated maltreatment often experience multiple forms of abuse [7].

a) EMOTIONAL ABUSE: It is seen as verbal, mental abuse, and psychosocial maltreatment. It includes acts or the failure to act by parents or caretakers that have consent or could cause, serious behavioural, cognitive emotional, or mental disorders [6].

b) SEXUAL ABUSE: the inappropriate sexual behaviour with a child. It includes fondling a child's genitals, making the child fondle the adult's genitals, intercourse, incest, rape, soloing, exhibitionism and sexual exploitation. To consider, child abuse, these acts have to be committed by a person responsible for the care of a child (e.g. a baby-sitter, a parent, or a daycare provider) or someone who is related to the child [10].

c) NEGLECT: the failure to provide for the child's basic needs neglect can be physical, educational, or emotional. Physical neglect can include not providing adequate food or clothing, appropriate medical core, supervision, or proper weather protection (haut or cots). It may include abandonment. Educational neglect includes. Failure to provide appropriate scooting or special educational needs, allowing excessive truancies. Psychological neglect includes the lack of any emotional support and love, never attending to the child, spousal abuse, clung and alcohol abuse including allowing the child to participate in drug and alcohol use physical abuse: the inflicting of physical impure upon a child [8]. This may include, brining, hitting, punching, shaking, kicking, beating, or otherwise harming a child [9].

\subsection{Incidences of Child Abuse and Neglect in Nigeria}

1) Child trafficking

2) 'Hawking on the street.

3) Begging in the street

4) Children living under the bridge

5) Children deprived of standard education

6) Exposing children to sexual harassments

7) Preventing child from proper medication

8) Child abduction

These and many more are incidences of child abuse in Nigeria
2.4 Factors affecting and contributing to Child Abuse and Neglect

Children and young people are affected by abuse and neglect in various ways. Outcomes of abuse may range from mild symptoms to debilitating and life-threatening conditions [14]. Factors that may affect the way in which abuse and neglect affects children and adolescents include:

1) the age and developmental status of the child when abuse occurred;

2) the severity of maltreatment;

3) the frequency and duration of maltreatment;

4) the relationship between the child and the perpetrator; and

5) The type(s) of abuse/neglect.

So many factors have in one way or the other brought about or increased the rate of child abuse in Nigeria. These causes may be as a result of certain activities and parental actions which has gone beyond control and has effected the Nigerian child some of these factors include: -

i. POVERTY: this factor has been seen to be one of the major causes of child abuse in Nigeria. It's responsible for the increasing number of street kids in the major Nigerian cities, - wherever there is a highly level of poverty take for instance in

Nigeria today, naturally you see people resorting to begging on the streets for a living because there is loss of jobs, dignity and the resulting effect will gradually shift to street begging [12].

Poverty has made so many children resort to sleeping under the bridge due to high cost of living and rent which the poor cannot afford, as such at this present state the child is prone to summary hazard that might be detrimental to his/her health and might eventually in one way or the other lead to death [13]

ii. DIVORCE: divorce is actually one thing that has also brought child abuse to its climax; it also has destroyed marriages etc [15]

In a situation where by a family/home is broken as a result of divorce, the children in such a home are left to themselves to do whatever they wish to do. At this point in time certain group may influence them to the detriment of their behavioral way of life and otherwise [16].

iii. LACK OF ATTENTION: anyone left to himself is prone to many things, parental love, care and attention truly matters in child upbringing. Lack of attention from parents to the children leaving them to house helps who tend to inculcate various ways of behavior into the children, this impacts actually makes them. Imagine a situation where 'both father and mother leaves home in the morning and is set to come back by midnight house, in this case the children set eye on their parents only on weekends 
not knowing what and what has transpired in their absence [11]

Until parents began to devote most of their time to the upbringing of their children, child abuse will have an upperhand in the society at large.

iv. DEATH: So many orphans have been exposed to child abuse at a very high rate considering the fact that they do not have parents any longer who take care of them or look after them.

Orphans who are left to their uncles and relatives after the death of their parents tend to suffer child abuse due to some level of hatred and wickedness from their aunts/ uncles. This wicked uncles might send this orphans to go hawking which exposes them to risk of death by accident, sexual harassment, rape and kidnap etc. and also poor feeding, maltreating them and sometimes they are not sent to school [17].

v. SOCIETAL INFLUENCE: This is seen from an ideology that indulging in under aged sex refreshes the blood.

Following the context, so many men of high age grade tend to sleep or rather make love to maidens as old as their daughters all in the name of a quest for fresh blood which I don't think is obtainable in such an act but is an abuse to the teenager involved in such a mess. It is no longer news to hear that a father impregnates his own daughter causing her unnecessary pains which are not worth it.

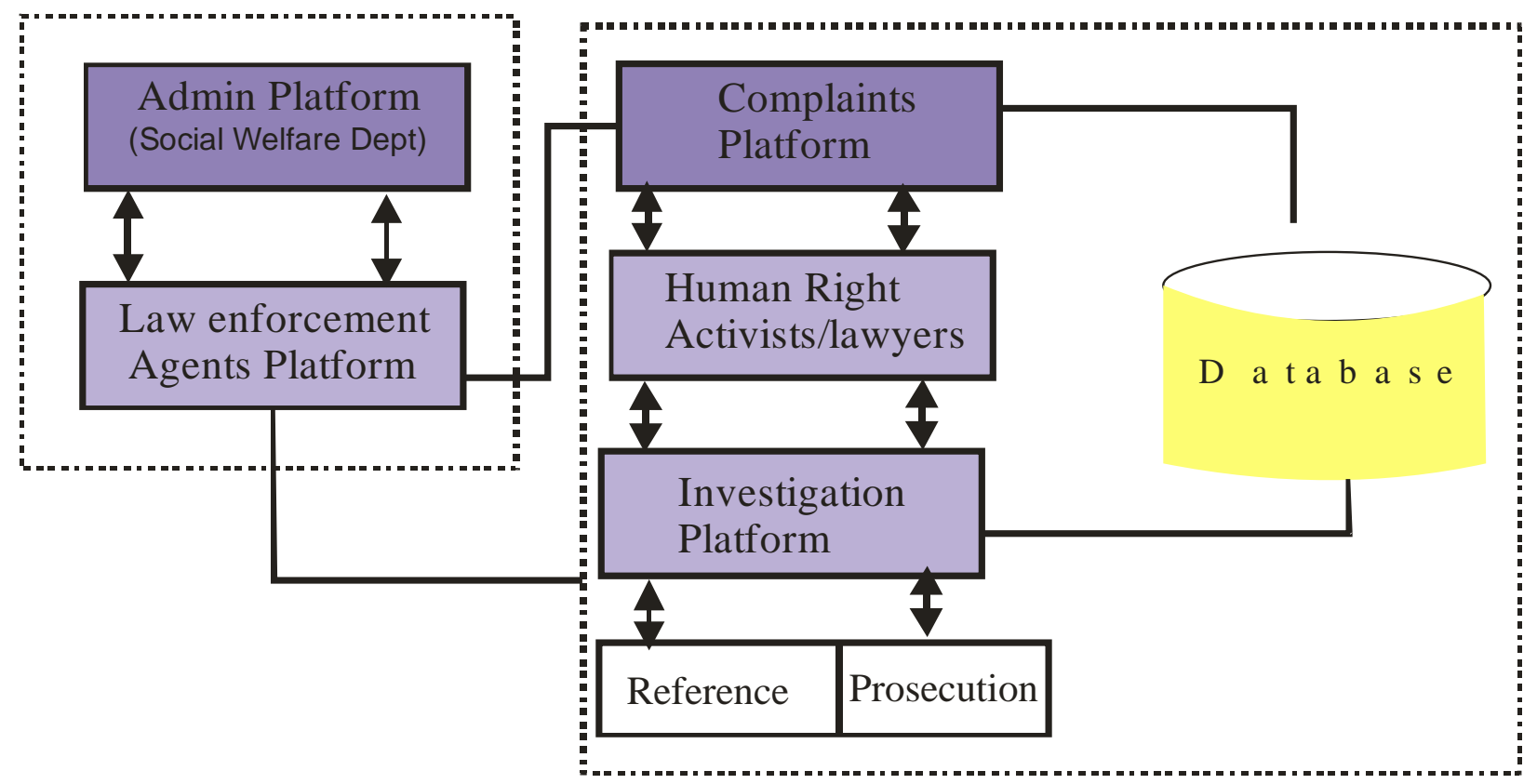

Fig.1: Architecture of Child Abuse Information System

The enhanced child abuse information system is divided into seven (7) parts, namely;

- Admin Platform: The administration platform is where the admin creates his account and he manages the information system. The admin also provides

\subsection{Child abuse database management system in Nigeria}

Documentations on child abuse complaints have been a nightmare in Nigerian context. Manual methods have been in existence which is prone to loss of document on transit, loss of integrity and security to alterations. Many organizations have proposed a computerized system of information system that will be able to manage child abuse complaints at every level and in each wards and local governments [8]. Lack of internet facilities and mobile network coverage has been a hindrance to this proposal, hence the need to develop alternative solutions like the use of short codes and telephone conversations. This research work proposes an enhanced child abuse information system that the complainant could drops his or her complaints when abused, law enforcement agents will verify the veracity of the reports, and the human rights activist and lawyers will appropriately prosecute the offenders. This is justifiable as there are no such systems that is functional in the Nigerian context and this results to the abused shy away from reporting such abused cases.

\section{MATERIALS AND METHODS}

In this paper, the processes and the implementation of child abuse information system is discussed. The figure 1 depicts the architectural design of the enhanced child abuse information management system. 
police and civil defense who are in-charge of civil matters. They investigates any complaint by the abused child as intimated by the human right lawyers and activists.

- Complaints platform: This platform is meant for the abused child to lodge his or her complaints.

- Human right activist/lawyers platform: The human right platform is for the people in-charge of public prosecutions and they work in tandem with the law enforcement agents. The platform allows them to create login details and access any complaints as will be designated by the admin.

- Investigation platform: This platform is where reports are created and suggestions on any concluded case are deposited for the public to view and it displays the actions taken on any matter.

- Reference platform: The reference platform renders help to human right activists and human right lawyers on previous cases handled and what punishment were meted on the offenders.

- Prosecution platform: This platform lists the names of the offenders

- The database: This serves as a repository for all the actions on the child abuse information system.

\subsection{System Analysis}

To properly analyze the system, the structured flow charts and flow diagram was employed.

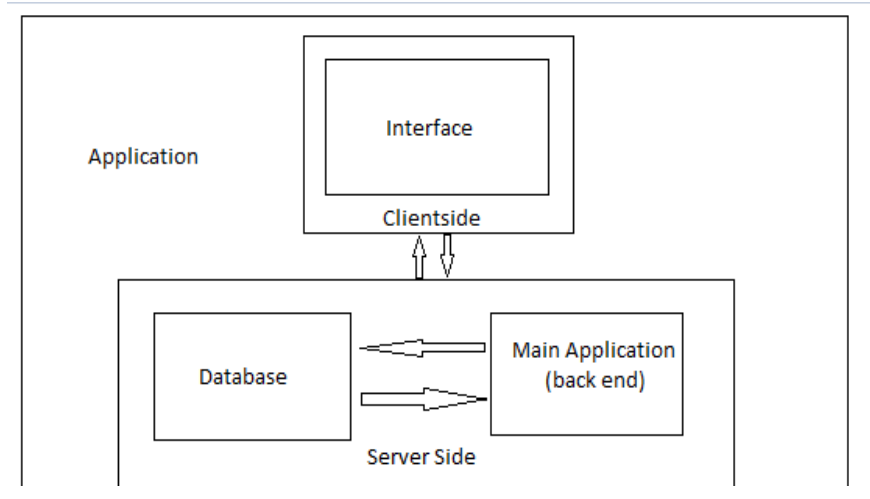

Fig 2: Block Diagram of Child Abuse Management System

The block diagram of the child abuse management system is grouped into 2 parts, as shown in fig 2 . The client side and the server side. The client side contains the interface of the system which serves as the main point of interaction between users and the child abuse management system. The server side consists of the database for storing information and the main application for processing all user requests from the interface. The main application also known as the backend is the centre of activity where all data processing are carried out and can also be seen as the backbone of the entire system.

\subsection{Structured Flow Chart of the System}

The flow chart of the system starts from the home page of the child abuse recording system offering the user the home page of the system where the user can access the report page or login as an admin. If the user is a reporter, the user can access a form to input details and complain to help the management handle their case. If the user logs in as an admin, he has the option of logging in as an admin. If the login details are not correct, a login error occurs and the user is presented with the login section to try to login again. On successful login, the user arrives the complaint page. The system verifies login details from the user before directing the user to the required page on the user interface. For this research, the Figure 3 shows the complete flow chart of the child abuse information system.

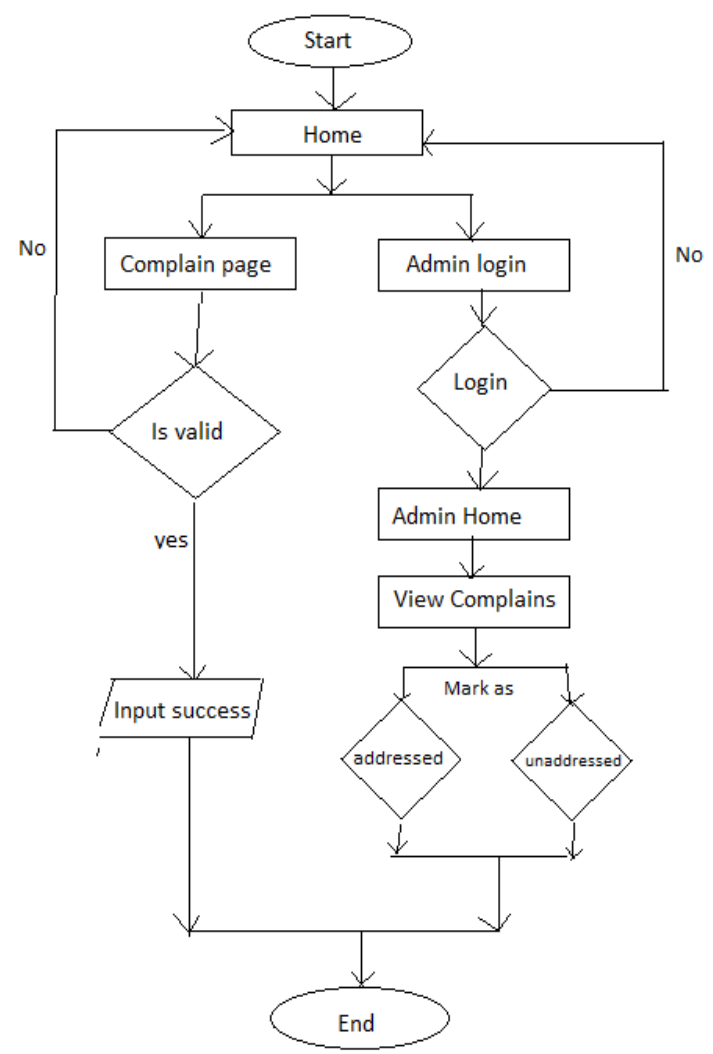

Fig.3 Flowchart of the System

\subsection{Data Flow Diagram of the System}

The data flow of the system starts from the backend of the system with the initialization of the system. After this, the system stays on standby awaiting input of data from the interface. The data from the user depending on the request goes to the backend of the system for processing. After processing, the result of the data goes back to the interface as shown in Figure 4. 


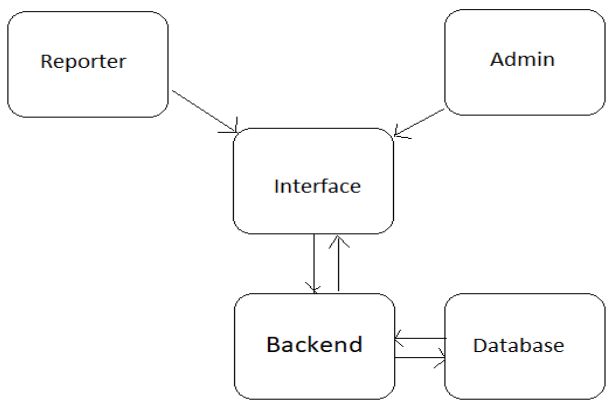

Fig. 4 Data Flow Diagram of Child Abuse Management System

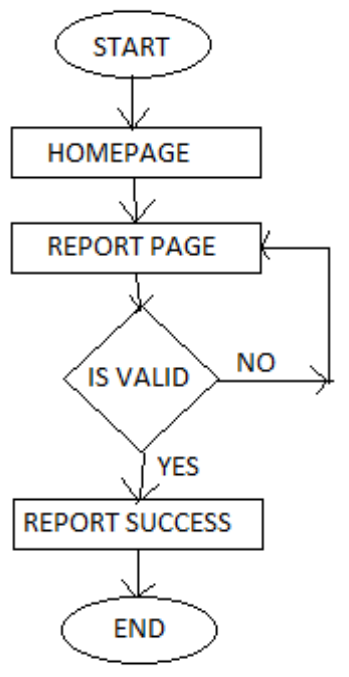

Fig. 5: Flow Chart of Report Module

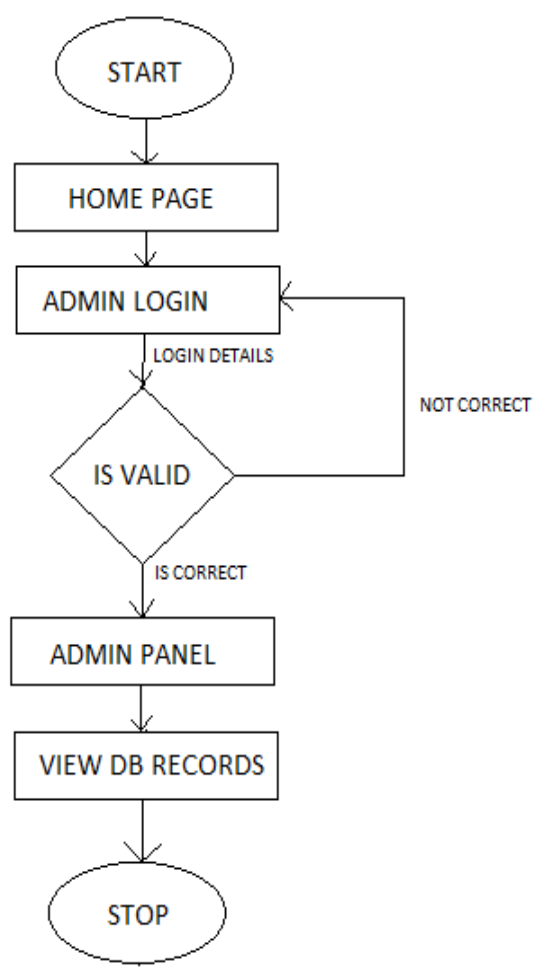

Fig. 6: Flow Chart for Admin Module
The database module deals with the storage, retrieval and update of data for system, the database module interacts with the interface in order to maintain the proper management of data flow in the system. Figures 5 and 6 show the flow chart of the report and admin modules respectively;

\subsection{Database Design}

The database of the Child abuse report system accommodates the minimum requirement of the system. The database management system used for the design of the database is MySQL. The database name consist of one table; the database design avoids data duplicity and redundancy. Figure 7 shows the structure of the database of the child abuse record system. The user's database is depicted in table 1 .

Table1: User's Database

DataBase

\begin{tabular}{|l} 
User's Table \\
$\qquad$\begin{tabular}{|l|c|c|}
\hline Filed Name & Size & Data Type \\
\hline id & 100 & int(32) \\
\hline First Name & 100 & String \\
\hline Last Name & 100 & String \\
\hline Repoter's Address & 100 & String \\
\hline Date & 10 & int(32) \\
\hline Victim's Sex & 1 & String \\
\hline E-mail & 50 & String \\
\hline Phone & 20 & int(32) \\
\hline Victim's Address & 50 & String \\
\hline Complains & 200 & String \\
\hline
\end{tabular}
\end{tabular}

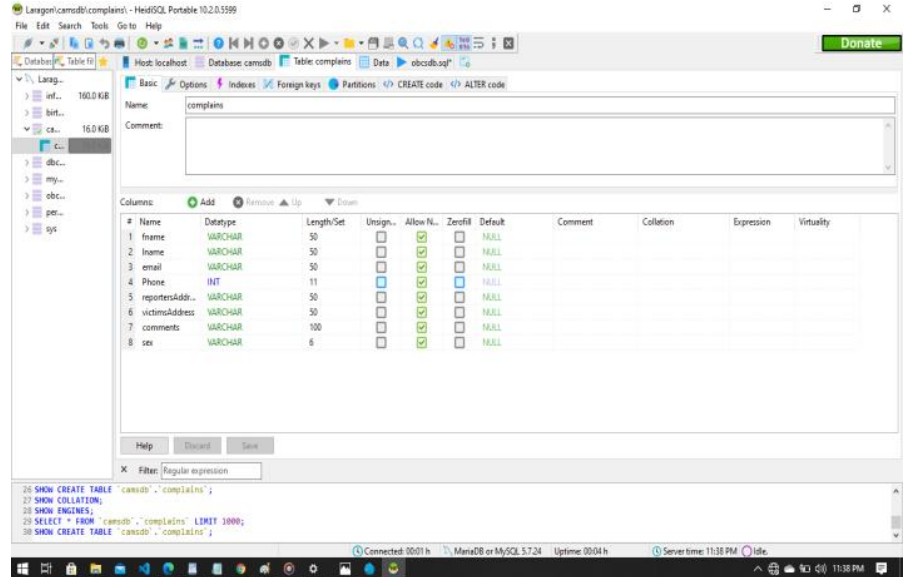

This serves as a repository for all 


\section{RESULTS AND DISCUSSIONS}

After putting all the necessary considerations for child abuse in Nigeria into action, interfaces were created using Visual Basic C-sharp at the front end and MYSQL as database at the back end as shown in figure 8 .

The interface of the Child abuse record system is the main point of interaction between the user and the backend end of the system. The main interfaces of the child abuse management system consist of the home page, the complaint page, the admin login page and the admin page.

The home page of the system displays the title of the project with login link on the top right of the page. The body of the home page gives a brief introduction of the web app. Buttons are present on the home page to take the user from home to about, complain and even admin log in page.

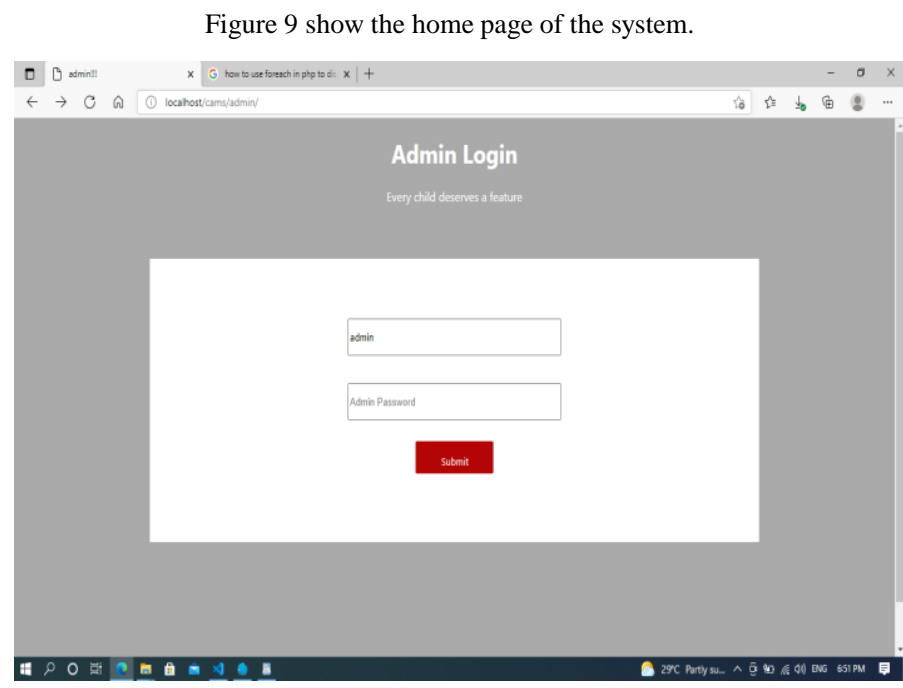

Fig. 8: Login Page

Figure 8 shows the login page of the information system, where the administrator of the application, that is those in the social welfare department, human right activists and law enforcement agents logs into the database and portal created.

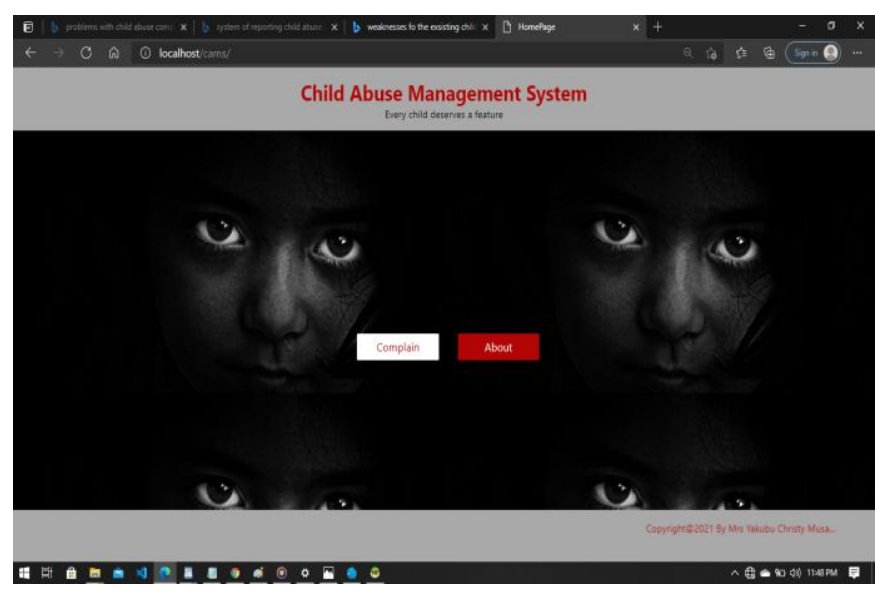

Fig.9: Home Page of Child Abuse Record System
The complainant does not have to create any user login, on the portal as shown in figure 8 , what he or she does, is just to complain, give the type of abuse, his or her address to be used in the contact as it is linked to figure 10 .

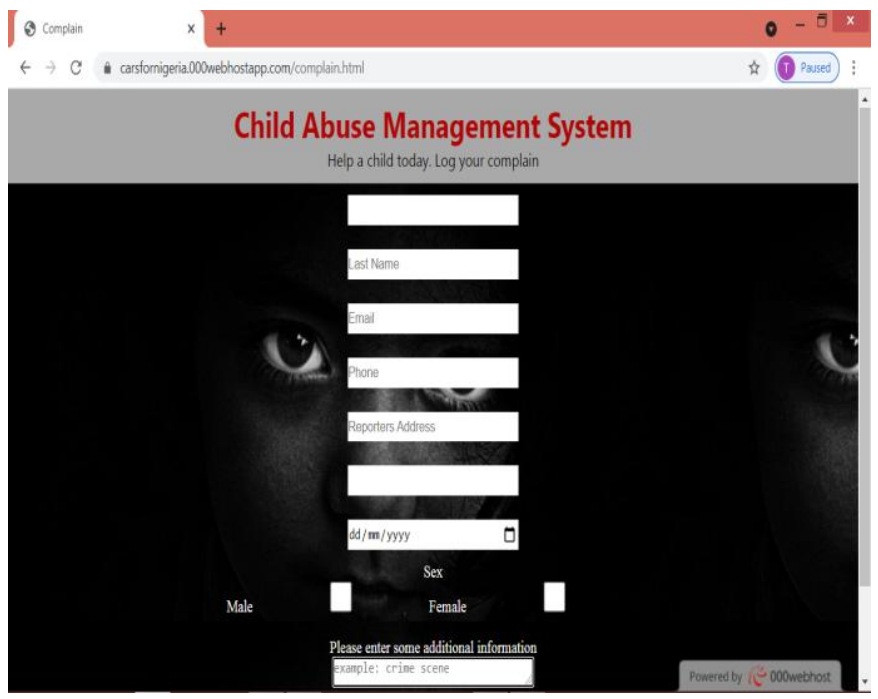

Fig. 10: Backend Design

The backend of the system is the main center of activity for the entire system, this where all data is processed and analyzed. The backend controls the flow of information and is designed to accommodate the minimum requirement of the Child abuse record system. The backend consist of three modules namely; the report module, the admin module.

The reporter module can be accessed from the home page of the web browser. The reporter first opens the web browser and navigates to the report page. After reporting a case, he is reefed to a screen showing that the complaint has been updated to the general database.

\section{CONCLUSION}

The Design and the Implementation of Child Abuse Management system was design to enable those who have been abused to make their complaints for proper investigation and documentation to be done and justice obtained. This is to enable the less privilege who have been abused have access to the platform without fear of any favouritism. The system will enable the social welfare departments in the country to work efficiently and effectively in managing child abuses in Nigeria, This system was designed using HTML, CSS, PHP and SQL which was tested and working. The system will help to reduce most of the problem related to Child Abuse records if implemented. The system comprises of people, equipment, space and procedures. In any software development, security is always a very important issue for consideration. This system is recommended to every one that is abused, the social welfare workers, the law enforcement agents and human right activists and the government in general. The administrators should therefore make use of authorized persons to take charge of the system. It is thus management obligation to ensure internal controls and security about the system, the 
system cannot be accessed by any user except the authorized user with the login ID and password.

\section{REFERENCES}

[1] Aber, J.L., and Cicchetti, D (2014) The socio-emotional development of maltreated children: An empirical and theoretical analysis. Pp. 147-205 in H. Fitzgerald, B. Lester, and M. Yogman (eds.) Theory and Research in Behavioral Pediatrics Vol. II. New York: Plenum Press.

[2] Abram, K. (2010) The problem of co-occurring disorders among jail detainees: Antisocial disorder, alcoholism, drug abuse, and depression. Law and Human Behavior 14:333-345.

[3] Alessandri, S.M. (2011) Play and social behavior in maltreated preschoolers. Development and Psycopathology 3:191-205.

[4] Alfaro, J.D (2011) Report on the relationship between child abuse and neglect and later socially deviant behavior. In R.J. Hunner and Y.E. Walker, eds., Exploring the Relationship Between Child Abuse and Delinquency. Montclair, NJ: Allanheld, Osmun.

[5] Allen, D.M (2010) Young male prostitutes: A psychosocial study. Archives of Sexual Behavior 9:399-426.

[6] Augoustinos, M. (2010) Developmental effects of child abuse: A number of recent findings. Child Abuse and Neglect 11:15-27.

[7] Ayoub, C.C., and Milner S.S. (2015) Failure to thrive parental indicators, types, and outcome. Child Abuse and Neglect 9:491499.

[8] Barahal, R.M (2010) The social and cognitive development of abused children. Journal of Consulting and Clinical Psychology 53:335-343.
[9] Bath, H. I., and Haapala. D. A (2013). "Intensive Family Preservation Services with Abused and Neglected Children: An Examination of Group Differences." Child Abuse \& Neglect 17(2): 213-225.

[10] Beck, J.C (2010) Reports of childhood incest and current behavior of chronically hospitalized psychotic women. American Journal of Psychitary 144(11):1474-1476.

[11] Benward, J., and Densen-Gerber, J (2015) Incest as a causative factor in antisocial behavior. Contemporary Drug Problems 4:323340.

[12] Berger, L. M. (2010). "Socioeconomic Factors and Substandard Parenting." Social Service Review 81(3): 485-522.

[13] Berger, L. M. (2014). "Income, Family Structure, and Child Maltreatment Risk." Children and Youth Services Review 26(8): 725-748.

[14] Berger, L. M. (2015). "Income, Family Characteristics, and Physical Violence toward Children." Child Abuse \& Neglect 29(2): 107-133.

[15] Bloom, H. S. (2011). The Core Analytics of Randomized Experiments for Social Research. New York: Manpower Demonstration Research Corporation.

[16] Braker, Stone M \& J.M Hellerstein (eds.) (1998). "Reading in databases". Kaufmann San Francisco

[17] Bonomi, R. S (2008). Association between self-reported health and physical and/or sexual abuse experienced before age 18. Child Abuse \& Neglect, 32(7), 693-701. 